\title{
High subcritical water-rock interaction for the formation of ferric minerals, in the absence of oxygen, UV light and microorganisms
}

\author{
Marie-Paule Bassez ${ }^{1, *}$ \\ ${ }^{1}$ Université de Strasbourg, Institut de Technologie, 67400 Illkirch, France
}

\begin{abstract}
The formation of ferric minerals on the anoxic early Earth is usually explained with the action of microorganisms or UV light in acidic conditions. Results show that amorphous and crystalline ferric oxides and silicates can form in the absence of oxygen, microorganisms and UV light, when rocks, located in the upper crust of the Earth until ca $1 \mathrm{~km}$ depth, contain ferrous silicates which interact with water called high subcritical, at $300-350{ }^{\circ} \mathrm{C}$ and $10-25 \mathrm{MPa}$. This conclusion is established following the analyses of Eh-pH diagrams for the $\mathrm{Fe}$ $\mathrm{H}_{2} \mathrm{O}$ system and solubility diagrams for quartz and amorphous silica. It is shown that water below the critical point and not above can lead to the formation of ferric iron in geological terrains on Earth and extraterrestrial objects where anoxic alkaline high subcritical water reacts with rocks containing ferrous silicates.
\end{abstract}

\section{Introduction}

Formation of the ferric iron which is observed inside the minerals hosted by rocks located in anoxic environments such as the Precambrian rocks up to the early Paleoproterozoic period is presently explained either with UV solar irradiation on the surface of acidic ocean water or with $\mathrm{Fe}(\mathrm{II})$-oxidizing or oxygen-producing microorganisms. A new hypothesis is presented to form ferric iron in alkaline conditions, in the upper crust of the Earth or extraterrestrial objects, where water can be near its critical point and not above. The Eh-pH diagrams drawn in 2012 [1] and analysed for this conclusion do not show ferrous oxidation in the supercritical state next to the critical point.

Until very recently, the reaction of serpentinization is usually written in a broad way as: olivine + pyroxene $+\mathrm{H}_{2} \mathrm{O}+\mathrm{CO}_{2} \rightarrow$ serpentine + talc + brucite + magnetite + quartz + carbonates + hydrogen. The ferric iron is included in the mineral magnetite. In 2007 an experiment was conducted at $200{ }^{\circ} \mathrm{C}$ and 500 bar, simulating subseafloor serpentinization reactions on the rock lherzolite peridotite [2]. The observation of the products led to the conclusion that magnetite was "surprisingly present in only trace amounts", and Mössbauer spectrometry analysis showed the presence of both $\mathrm{Fe}^{2+}$ and $\mathrm{Fe}^{3+}$ in the product serpentine with $58 \%$ of the total $\mathrm{Fe}$ as ferrous iron and $42 \%$ as ferric iron.

\footnotetext{
*Corresponding author: marie-paule.bassez@unistra.fr
} 
A careful reading of Table 4 in [2] shows that, from ca 5 to 11 months, $\mathrm{pH}$ reaches a constant value of 12.1 and the dissolved species $\mathrm{Na}$ and $\mathrm{K}$ and $\mathrm{H}_{2}$ reach also approximately their upper values. Thus, $\mathrm{H}_{2}$ seems to be produced at $200{ }^{\circ} \mathrm{C}, 500 \mathrm{bar}$, in water with a peridotite without sulphides, at an alkaline $\mathrm{pH}$ which can be provided by $\mathrm{NaOH}$ or $\mathrm{KOH}$. Magnetite is not the produced ferric species and ferric iron appears to be incorporated inside serpentine. During the context of my research on the origin of life, the above experimental observations could be coevally explained. The following analyses and calculations led to the conclusion that ferric iron can be produced in anoxic geological environment where the conditions of temperature and pressure of water are those called high subcritical, hsubc.

\section{Methods}

The method for the analysis of minerals is a logical association and composition of my theoretical analyses of diagrams and experimental results published by other scientists, of my thermodynamic calculations on hydrolyses and carbonations of the olivine and pyroxene endmembers [3-6] and of my Raman analysis of minerals observed in a core drilled in the Barberton greenstone belt [7]. The diagrams and the methods used for the analyses are presented in detail in [8]. The redox Eh-pH Pourbaix diagrams for the $\mathrm{Fe}-\mathrm{H}_{2} \mathrm{O}$ system and the solubility diagrams for quartz and amorphous silica, are analysed for high subcritical water. Liquid water in the temperature range $100-374{ }^{\circ} \mathrm{C}$ and under pressurized conditions is called subcritical. The high subcritical domain starts around $300^{\circ} \mathrm{C}$ and $10 \mathrm{MPa}$.

\section{Results}

\subsection{Formation of ferric iron in anoxic alkaline high subcritical water}

Since 2013, a new path for the formation of ferric iron and ferric minerals in anoxic alkaline water has been published [3-8].

Results show the decomposition of the serpentinization reaction into 9 elementary chemical reactions of hydrolyses, carbonations and dehydration, with the corresponding calculated thermodynamic functions, enthalpies, entropies and free enthalpies. Calculations obtained with thermodynamic data given at $25^{\circ} \mathrm{C}$, show that all carbonations and hydrolyses of the $\mathrm{Mg}$ endmembers of olivine and pyroxene are exothermic and that the hydrolyses of the $\mathrm{Fe}$ endmembers are endothermic and produce $\mathrm{H}_{2}$. The hydrolyses of the Fe-endmembers can proceed within the heat produced by the other reactions or by any other kind of heat input. Results show also the oxidation of $\mathrm{Fe}^{2+}$ into $\mathrm{Fe}^{3+}$ in anoxic alkaline high subcritical water as written in equations (1) and (2). These equations can be expressed following the analysis of redox Eh-pH Pourbaix diagrams drawn for $10^{-6}, 10^{-8}$ and $10^{-11} \mathrm{~mol} / \mathrm{kg}$ of product species dissolved in high subcritical and supercritical water in [1]. They represent the oxidation of ferrous iron into ferric iron in anoxic and alkaline water near its critical point, at $300-350{ }^{\circ} \mathrm{C}$, $10-25 \mathrm{MPa}, 9.5<\mathrm{pH}<14$.

$$
\begin{aligned}
& \mathrm{Fe}^{\mathrm{II}}(\mathrm{OH})_{3}^{-}+\mathrm{H}_{2} \mathrm{O}_{h s u b c} \rightarrow \mathrm{Fe}^{I I I}(\mathrm{OH})_{4}^{-}+1 / 2 \mathrm{H}_{2} \\
& \mathrm{Fe}^{2+}+\mathrm{H}^{+} \rightarrow \mathrm{Fe}^{3+}+1 / 2 \mathrm{H}_{2}
\end{aligned}
$$

In 2017 [5, 6] and 2018 [7], results were published considering fayalite and ferrosilite hydrolyses, with the oxide magnetite $\mathrm{FeOFe}_{2} \mathrm{O}_{3}$ as product, and also with the oxide hydroxides, ferric trihydroxide, $\mathrm{FeO}(\mathrm{OH}) \mathrm{H}_{2} \mathrm{O}$, goethite $\alpha-\mathrm{FeO}(\mathrm{OH})$, lepidocrocite $\gamma-\mathrm{FeO}(\mathrm{OH})$ and the oxide hematite $\mathrm{Fe}_{2} \mathrm{O}_{3}$. It is shown that magnetite is not the primary product of the oxidation of ferrous iron. Goethite and hematite form and ferric iron can be incorporated into the serpentine group. 
Indeed, fayalite dissolves in hsubc water producing the ferrous iron $\mathrm{Fe}^{2+}$ and silica. This process can be predicted by the analysis of solubility diagrams drawn for quartz and amorphous silica $[7,9,10]$. In alkaline hsubc water $\mathrm{Fe}^{2+}$ is oxidized into $\mathrm{Fe}^{3+}$ which is incorporated in the ferric tetrahydroxide anion $\mathrm{Fe}^{\mathrm{III}}(\mathrm{OH})_{4}^{-}$which is in fact the anionic form of hydrated goethite, $\mathrm{Fe}^{\mathrm{III}} \mathrm{O}(\mathrm{OH}) \mathrm{H}_{2} \mathrm{O}(\mathrm{OH})^{-}$, in other words, the dissolved form of hydrated goethite. Consecutively, goethite $\alpha-\mathrm{Fe}^{\mathrm{III}} \mathrm{O}(\mathrm{OH})$ and lepidocrocite $\gamma-\mathrm{Fe} \mathrm{e}^{\mathrm{III}} \mathrm{O}(\mathrm{OH})$ form by dehydration, and also hematite. Experiments heating natural goethite produced hematite between $260^{\circ} \mathrm{C}$ and $360^{\circ} \mathrm{C}$ and magnetite at $685^{\circ} \mathrm{C}$ [11]. However, the formation of magnetite appears to depend also upon water in high subcritical conditions through the hydrolysis of siderite as observed in 2015 in an experiment conducted at $300{ }^{\circ} \mathrm{C}$ and $50 \mathrm{MPa}$ [12]. The equation for the hydrolysis of siderite [12] is written in equation (3) with the subscripts diss and hsubc, to highlight water in its high subcritical domain [8].

$$
3 \mathrm{FeCO}_{3(s)}+\mathrm{H}_{2} \mathrm{O}_{\text {hsubc }} \rightarrow \mathrm{Fe}_{3} \mathrm{O}_{4}+3 \mathrm{CO}_{2 \text { diss }}+\mathrm{H}_{2 \text { diss }}
$$

The ferric iron $\mathrm{Fe}^{3+}$ can be incorporated inside Fe-chrysotile which is greenalite. Indeed, in 2016 an anoxic mixture of $\mathrm{Fe}^{2+}$ and $\mathrm{SiO}_{2}$ dissolved in water at $25^{\circ} \mathrm{C}$, produced a "hydrated disordered $\mathrm{Fe}^{2+}$ - silicate gel" which dehydrated into greenalite [13]. The silicate greenalite, $\mathrm{Fe}_{3}{ }_{3} \mathrm{Si}_{2} \mathrm{O}_{5}(\mathrm{OH})_{4}$, is the iron equivalent of the serpentine chrysotile, $\mathrm{Mg}_{3} \mathrm{Si}_{2} \mathrm{O}_{5}(\mathrm{OH})_{4}$. In high subcritical water, $\mathrm{Fe}^{2+}$ is oxidized into $\mathrm{Fe}^{3+}$, consequently, the hydrated disordered ferrous, ferric- silicate gel, $\left(\mathrm{Fe}^{\mathrm{II}}, \mathrm{Fe}^{\mathrm{III}}\right)_{2-}{ }_{3} \mathrm{Si}_{2} \mathrm{O}_{5}(\mathrm{OH})_{4}$, should form and dehydrate into $\mathrm{Fe}^{\mathrm{II}}, \mathrm{Fe}^{\mathrm{III}}$ greenalite [7].

The experiment [2] can be thus be explained. $\mathrm{H}_{2}$ and $\mathrm{Fe}^{3+}$ are produced in an alkaline anoxic solution when a rock containing $\mathrm{Fe}^{2+}$ and no sulfur is hydrolyzed at $\mathrm{T}$ and $\mathrm{P}$ near the critical point of water. Magnetite is not formed since water is not carbonated and $\mathrm{Fe}^{3+}$ is incorporated into $\mathrm{Fe}^{\mathrm{III}}$ - silicates such as $\mathrm{Fe}^{\mathrm{III}}$ - greenalite.

Therefore, the hydrolysis of rocks containing ferrous silicates, by anoxic, alkaline, high subcritical water, leads to quartz and amorphous silica, the ferric oxides goethite, lepidocrocite, hematite, the disordered silicate gel $\left(\mathrm{Fe}^{\mathrm{II}}, \mathrm{Fe}^{\mathrm{III}}\right)_{2-}{ }_{3} \mathrm{Si}_{2} \mathrm{O}_{5}(\mathrm{OH})_{4}$, the silicates $\mathrm{Fe}^{\mathrm{II}}, \mathrm{Fe}^{\mathrm{III}}$-greenalite and $\mathrm{Fe}^{\mathrm{II}}, \mathrm{Fe}^{\mathrm{III}}$-minnesotaite and to the carbonate siderite which leads to magnetite. Riebeckite and stilpnomelane which, to my knowledge, can be considered as dehydrated products of greenalite, may form also. Magnetite should be observed in terrains including siderite. These minerals are those observed in banded iron formations of early Earth. They are summarized in Figure 1.

\subsection{Formation of ferric minerals in geological terrains}

The formation of ferric iron in high subcritical water has never been evoked for the understanding of any kind of geological terrains, until my proposition in 2013 [3]. However, in many cases of the geological world, water can be in high subcritical conditions of temperature and pressure and induce the formation of ferric compounds. Such plausible process is described below for rocks located in anoxic environments.

As illustrated in Figure 2, circulating water, rich in carbon dioxide and undersaturated in silica, is heated near magma chambers, rises, encounters rocks hosting ferrous iron such as peridotite lherzolite containing fayalite, $\mathrm{KOH}$ and $\mathrm{NaOH}$, and becomes alkaline. When the fayalitic massif is located near the surface of the Earth, within approximately $1 \mathrm{~km}$ of the upper crust, the lithostatic pressure is 10 to $25 \mathrm{MPa}$. Indeed, a rock column of ca $850 \mathrm{~m}$ with an average density of $3 \mathrm{~g} / \mathrm{cm}^{3}$ produces a lithostatic pressure of $25 \mathrm{MPa}$. If the rising water encountering fayalite has a temperature of ca $300-350{ }^{\circ} \mathrm{C}$, ferrous iron is oxidized into ferric iron. The dissolution of the silicates fayalite and ferrosilite is enhanced by the fact that amorphous and crystalline silica dissolve well up to the critical point of water and not above 
and also by the fact that silica adsorbs onto hematite $[14,7]$, lowering thus the silica content in the solution and inducing further dissolution of fayalite and ferrosilite to produce dissolved silica.

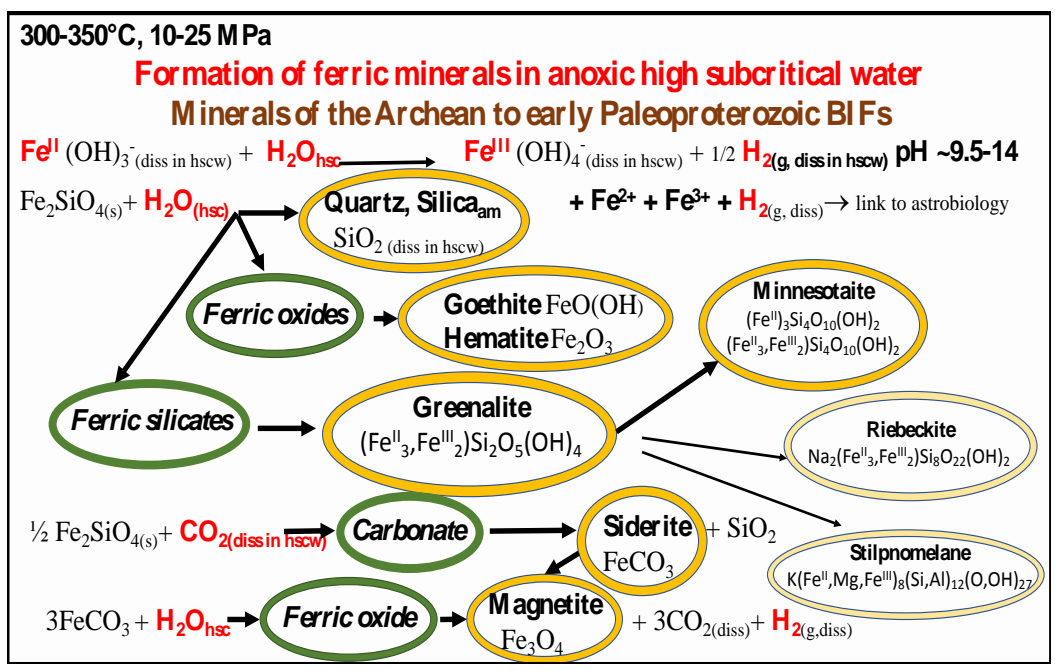

Fig. 1. A possible formation of ferric minerals in the absence of UV light, oxygen and microorganisms. The synthesized minerals are: quartz \& amorphous silica; the ferric oxides goethite and hematite; magnetite is formed from siderite; the ferric silicates greenalite and its dehydration product minnesotaite, and riebeckite and stilpnomelane which may possibly be considered as dehydration products of greenalite. The figure is improved from [7] and is published in [8].

Thus, a kind of magmatic hydrothermal system can be generated with a shallow reaction chamber containing fayalite, ferrosilite, anoxic alkaline hsubc water and where the minerals described in $\$ 3.1$ and Figure 1 form. The carbonated water stagnates inside pores and spaces of the fayalitic rock, dissolving the rock and leading to minerals with increased volumes, such as the carbonated and amorphous minerals. It is known that hydration and carbonation of $\mathrm{Mg}$ olivine result in ca 44\% increase in solid molar volume [15 and refs herein]. This large volume change generates stresses and strains creating cracks which increase the porosity of the rock and its permeability and consequently its reaction with hsubc water. Repeated volume-expanding reactions can thus be at the origin of episodic fracturing of the rock. "Forces generated by the volume increase should be enough to fracture peridotite" [15]. Stresses and cracks are also generated by the different rates of expansion following the different precipitation rates of the products $[15,16]$. Therefore, it is plausible that high subcritical water flows from linear fractures of the shallow reaction chamber into several conduits, and finally escapes on the ocean floor out of venting arcs and/or fissure eruptions, entraining minerals which are the products of the hydrolysis and carbonation of fayalite. The ejection is favored by the increase in pressure consecutive to the continuous release of $\mathrm{H}_{2}$ and by the increase in heat released as a consequence of exothermic reactions [3-6]. As shown in Table 1 in [8] the relative densities, also called specific gravities, of the products of hydrolyses and carbonations of ferrous rocks are very different, and consequently induce inhomogeneous flows inside the conduits producing self-ordered convective flow structures such as dissipative structures which continuously dissipate and redevelop. Intertwined columnar flows can most probably form, each filled with hsubc water containing minerals with specific densities. In the future, it would be most interesting to modelize such flows.

Therefore, the ferric minerals observed in rocks containing ferrous iron, can be explained by this interaction between rock and the water which is anoxic, alkaline and high subcritical. 


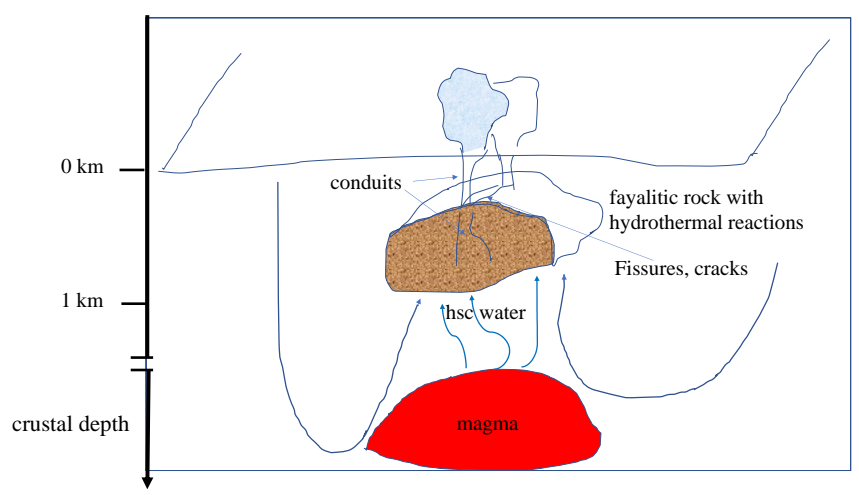

Fig. 2. A schematic illustration of a kind of magmatic hydrothermal reaction chamber (after [8]). The $\mathrm{H}_{2}$ released can be captured inside inclusions, together with $\mathrm{CO}_{2}$ and $\mathrm{N}_{2}$, to form components of life [3-8].

\section{Conclusion}

Therefore, alkaline high subcritical water appears to explain the formation of ferric minerals in anoxic geological terrains containing ferrous silicates, illustrating the following words: "Water and igneous rocks of basic and ultrabasic compositions create an abiogenic dissipative system...that is capable of maintaining...the formation of numerous new minerals that are paragenetically associated with specific geochemical types of water." [17].

With the new hypothesis for the formation of ferric iron, developed since 2013 [3-8], neither the action of UV light, nor oxygen, nor any kind of microorganisms is required to explain the origin of ferric minerals. A large amount of ferric minerals could thus be synthesized in Precambrian eon, from Archean era to early Paleoproterozoic period, without the necessity for them to approach the millimeter lane of the ocean surface in order to be submitted to UV radiation, nor the necessity of any kind of reaction with oxygen, nor Fe(II)-oxidizing microorganisms.

\section{References}

1. W.G. Cook, P. R. Olive, Corros Sci, 55, 326-331 (2012)

2. W.E. Seyfried, et al., Geochim Cosmochim Acta, 71, 3872-3886 (2007)

3. M.-P. Bassez, EGU, Geophysical Research Abstract, 15, PS8.1 EGU2013-22

4. M.-P. Bassez, Orig Life Evol Biosph, 45, 5-13 (2015)

5. M.-P. Bassez, Orig Life Evol Biosph, 47, 453-480 (2017)

6. M.-P. Bassez, Proc Earth Planet Sci, WRI-15, 17, 492-495 (2017)

7. M.-P. Bassez, Orig Life Evol Biosph, 48, 289-320 (2018)

8. M.-P. Bassez, Geosci Spec Issue Planet Evol Search Life, (2019, in press)

9. P. Karasek, et al., J Supercrit Fluids, 83, 72 (2013)

10. R.L. Smith Jr, Z. Fang, Fluid Phase Equilib, 302, 65-73 (2011)

11. M.J. Dekkers, Geoph J Int, 103, 233-250 (1990)

12. V. Milesi, et al., Geochim Cosmochim Acta, 154, 201-211 (2015)

13. N.J. Tosca, et al., Geol Soc Am Bull, 128, 511-530 (2016)

14. O. Qafoku, et al., Chem Geol, 332-333, 124-135 (2012)

15. T. Xing, Wet al., Solid Earth, 9, 879-896 (2018) 
16. W. Zhu, et al., Geophys Res Lett, 43, 9535-9543 (2016)

17. S. Shvartsev, Geodynam Tectonophys, 9, 1275-1291 (2018) 